\title{
Effects of hyperbaric oxygen therapy on RAGE and MCP-1 expression in rats with spinal cord injury
}

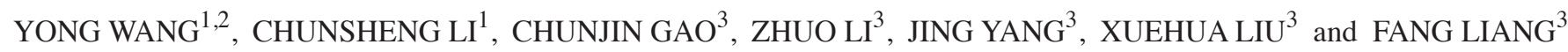 \\ ${ }^{1}$ Department of Emergency, Beijing Chaoyang Hospital, Capital Medical University, Beijing 100020; \\ ${ }^{2}$ Department of Hyperbaric Oxygen, Fuxing Hospital, Capital Medical University, Beijing 100038; \\ ${ }^{3}$ Department of Hyperbaric Oxygen, Beijing Chaoyang Hospital, Capital Medical University, Beijing 100020, P.R. China
}

Received July 5, 2015; Accepted August 19, 2016

DOI: $10.3892 / \mathrm{mmr} .2016 .5935$

\begin{abstract}
The inflammatory response is an important source of secondary damage to neuronal tissue in the spinal cord following spinal cord injury (SCI). Hyperbaric oxygen (HBO) therapy reduces inflammation and promotes the restoration of locomotor function following SCI, however, the mechanisms underlying this effect remain to be determined. The aim of the current study was to investigate the mechanisms by which HBO therapy promotes recovery in a rat model of SCI by measuring expression levels of receptor for advanced glycation end products (RAGE) and monocyte chemoattractant protein-1 (MCP-1) in spinal cord tissue. Experimental animals $(n=90)$ were divided into three groups: Sham-operated (SH), SCI (T-10 laminectomy) and SCI + HBO. Each group was further divided into five subgroups $(\mathrm{n}=6)$ that were examined at $12 \mathrm{~h}$, and at 1 , 3, 7 and 14 days post-injury. Recovery of locomotor function was evaluated using the Basso, Beattie and Bresnahan (BBB) scoring system. Neutrophil infiltration was analyzed using myeloperoxidase (MPO) activity assays. The expression of RAGE and MCP-1 was measured by immunohistochemistry, reverse transcription-quantitative polymerase chain reaction and western blotting. RAGE and MCP-1 expression and MPO activity were higher in the SCI groups than in the SH groups at each time point. HBO therapy reduced RAGE and MCP-1 expression and MPO activity compared with untreated, injured animals at early post-injury stages. In addition, HBO therapy improved BBB scores at post-operative day 7 and 14. HBO therapy was, therefore, demonstrated to relieve secondary inflammatory responses, potentially by inhibiting the expression of RAGE and MCP-1, resulting in significant recovery of locomotor function. The results of the present study may, therefore,
\end{abstract}

Correspondence to: Dr Chunsheng Li, Department of Emergency, Beijing Chaoyang Hospital, Capital Medical University, 8 Gongti South Road, Chaoyang, Beijing 100020, P.R. China

E-mail: chunsheng11912@163.com

Key words: hyperbaric oxygen treatment, spinal cord injury, receptor for advanced glycation end products, monocyte chemoattractant protein-1 be useful in improving the clinical application of HBO therapy for patients with SCI.

\section{Introduction}

The pathogenesis of spinal cord injury (SCI) involves two phases: A primary trauma, which is pivotal for initial tissue disruption, followed by a series of secondary cellular processes that accentuate tissue damage beyond the original injury site and that can lead to long-term functional spinal deficits and disabilities (1). Although considerable effort has been made to improve outcomes for patients with SCI, advances in therapy for this disease have been limited, and further efforts are necessary to improve the treatment of SCI. Previous reports have suggested that hyperbaric oxygen (HBO) therapy is beneficial for neurological recovery in SCI, and $\mathrm{HBO}$ has become an important therapeutic approach in the treatment of secondary SCI $(2,3)$. However, the mechanism that underlies this effect is not well understood. The inflammatory response is an important source of secondary damage to neuronal tissue in the spinal cord following SCI (4). Receptor for advanced glycation end products (RAGE) binds diverse ligands, including the high mobility group box-1 (HMGB1) and S100 calcium binding protein families $(5,6)$. Ligand binding to RAGE triggers a series of cellular signaling events, including the activation of nuclear factor- $\kappa \mathrm{B}$ $(\mathrm{NF}-\kappa \mathrm{B})$, which leads to pro-inflammatory cytokine production and causes inflammation (7). Abnormal upregulation and activation of RAGE is associated with diseases of the central nervous system (CNS), including traumatic brain injury, ischemic stroke and SCI (8-10). Monocyte chemoattractant protein-1 (MCP-1) is a member of the $\beta$-chemokine family that activates and recruits mononuclear phagocytes, T cells and B cells, and is induced in response to various CNS insults (11-13). However, previous studies have not addressed the effect of $\mathrm{HBO}$ on the expression of RAGE and MCP-1 following SCI. In the present study, $\mathrm{HBO}$-induced changes in RAGE and MCP-1 expression levels were investigated in rats following SCI, and the effect of $\mathrm{HBO}$ therapy on SCI recovery was investigated.

\section{Materials and methods}

Animals. A total of 90 8-week-old adult Sprague-Dawley rats (Center of Experimental Animals of Capital Medical 
University, Beijing, China) weighing 220-250 g were maintained under environmentally controlled conditions and subject to a $12 \mathrm{~h}$ light/dark cycle, with food and water provided ad libitum. The animals were acclimated to the facility for 7 days prior to initiation of experimentation, then were divided into sham-operated (SH), SCI, and SCI + HBO groups using the randomization table method. Each group was further divided into five subgroups, each containing six animals, that were evaluated at $12 \mathrm{~h}$, and 1, 3, 7 and 14 days post-injury. All procedures and handling techniques were in strict accordance with the Committee on the Ethics of Animal Experiments of Capital Medical University (Beijing, China).

Spinal cord injury. Traumatic spinal injury was induced using a Multicenter Animal SCI Study Impactor weight drop device (14). Briefly, the rats were anesthetized with $10 \%$ chloral hydrate $(350 \mathrm{mg} / \mathrm{kg}$ ) administered intraperitoneally. The fur above the vertebral column was cleared using clippers and cleaned with Betadine solution. A $20-\mathrm{mm}$ midline incision was made in the thoracic region, and the vertebral column was exposed. A laminectomy was performed at the T-10 vertebra, exposing the dorsal cord surface with the dura intact. The vertebral column was stabilized with angled clamps on the T-8 and T-12 vertebrae. A 10-g weight was dropped from $25 \mathrm{~mm}$ onto the T-10 segment, resulting in a moderate spinal cord injury. The impact rod was removed immediately following the injury, and the muscles and the incision were closed in layers. Following surgery, animals were placed on a heating pad maintained at $37^{\circ} \mathrm{C}$ and monitored until recovery from anesthesia, then returned to the cages. A single dose of penicillin $(0.8 \mathrm{mg} / \mathrm{g})$ was administered daily by subcutaneous injection until hematuria ceased. Manual bladder expression was required daily until a reflex bladder was established. The sham-operated rats received the equivalent surgical procedure, but were not subjected to impact injury.

$\mathrm{HBO}$ therapy. Rats in the SCI + $\mathrm{HBO}$ group were placed in a hyperbaric chamber for $6 \mathrm{~h}$ post-surgery and exposed to 2.0 atmospheres absolute (ATA) of $100 \%$ oxygen for $60 \mathrm{~min}$ once daily. Following treatment, the chamber was flushed with $100 \%$ oxygen for $5 \mathrm{~min}$, then the pressure was increased to 2.0 ATA for 10 min, followed by slow decompression over $15 \mathrm{~min}$ to normobaric air (21\% oxygen). Rats in the SH and SCI groups were post-operatively treated with normobaric air at 1.0 ATA.

Assessment of locomotor function. Recovery of locomotor function was assessed using an open-field testing paradigm, the Basso-Beattie-Bresnahan (BBB) Locomotor Rating Scale, which is based on a 21-point scale originally developed in spinal cord-injured rats (15). This scale assesses 10 distinct categories, ranging from limb movement to tail position, and involves detailed observations of joint movement, stepping and coordination. Uninjured animals exhibit a locomotor score of 21 , whereas animals that exhibit complete hind limb paralysis are scored as 0 . All animals were scored in an open field $(120 \times 120 \mathrm{~cm})$ for $5 \mathrm{~min}$ at $12 \mathrm{~h}$ and at 1,3,7 and 14 days post-injury.

Tissue sample collection. Terminally anesthetized (10\% chloral hydrate by intraperitoneal injection at a dose of
$350 \mathrm{mg} / \mathrm{kg}$ ) rats were transcardially perfused with cold saline and $4 \%$ buffered paraformaldehyde at the indicated time points post-surgery (12 $\mathrm{h}$ and 1, 3, 7 and 14 days). The spinal cord containing the injured center site was removed and divided into two segments: One was fixed with $10 \%$ formaldehyde solution at $4^{\circ} \mathrm{C}$ for 1 week for histological evaluation, and the remaining segment was preserved at $-80^{\circ} \mathrm{C}$ for molecular analyses.

Myeloperoxidase (MPO) activity assay. MPO activity, an indicator of polymorphonuclear leukocyte accumulation, was determined in the spinal cord tissue as previously described (16). Each tissue sample was weighed, then homogenized in homogenate medium $[0.5 \%(\mathrm{w} / \mathrm{v})$ hexadecyltrimethyl-ammonium bromide dissolved in $10 \mathrm{mM}$ potassium phosphate buffer, $\mathrm{pH}$ 7] and centrifuged at $20,000 \times \mathrm{g}$ for $30 \mathrm{~min}$ at $4^{\circ} \mathrm{C}$. An aliquot of the supernatant was subsequently incubated with a solution of $1.6 \mathrm{mM}$ tetramethyl-benzidine and $0.1 \mathrm{mM} \mathrm{H}_{2} \mathrm{O}_{2}$. The rate of change in absorbance was measured using a UV-2000 UV/ Vis spectrophotometer (Unico Shanghai Instrument Co. Ltd., Shanghai, China) at $460 \mathrm{~nm}$. MPO activity was defined as the quantity of enzyme required to degrade $1 \mathrm{mmol} \mathrm{H}_{2} \mathrm{O}_{2}$ per min at $37^{\circ} \mathrm{C}$ and was expressed as units of $\mathrm{MPO} / \mathrm{g}$ wet tissue.

Immunohistochemical staining. Histopathological samples were fixed, embedded in paraffin, and cut into 5- $\mu \mathrm{m}$ slices. Following deparaffinizing and rehydrating, antigen retrieval was performed according to standard protocols (17). Following treatment with $3 \% \mathrm{H}_{2} \mathrm{O}_{2}$ in methanol and normal non-immune goat serum (Invitrogen; Thermo Fisher Scientific, Inc., Waltham, MA, USA) for $20 \mathrm{~min}$ at room temperature, the sections were incubated overnight at $4^{\circ} \mathrm{C}$ with primary antibodies against RAGE (1:1,000; catalog no. sc-365154; Santa Cruz Biotechnology, Inc., Dallas, TX, USA) or MCP-1 (1:2,000; catalog no. sc-28879; Santa Cruz Biotechnology, Inc.). The sections were then incubated with biotinylated-goat anti-rabbit immunoglobulin $\mathrm{G}(1: 5,000$; catalog no. K500710; Dako, Glostrup, Denmark) for $50 \mathrm{~min}$ at room temperature, then treated with streptavidin-peroxidase (Dako). Phosphate-buffered saline was used in place of the primary antibody in the negative control samples. Diaminobenzidine was used to visualize peroxidase activity, and sections were counterstained with hematoxylin. Five fields on each of the three slides per animal were randomly selected for visualization by light microscopy. Images were analyzed using Image-Pro Plus 6.0 software (Media Cybernetics, Inc., Rockville, MD, USA).

Reverse transcription-quantitative polymerase chain reaction $(R T-q P C R)$. Total RNA $(5 \mu \mathrm{g})$ was extracted from frozen spinal cord tissue using TRIzol reagent (Invitrogen; Thermo Fisher Scientific, Inc.) and an extraction kit (Takara Bio, Inc., Otsu, Japan), according to manufacturer protocols. First-strand cDNA synthesis from $2 \mu \mathrm{g}$ RNA was performed using Moloney Murine Leukemia Virus reverse transcriptase (BIOER, Hangzhou, China), with a temperature protocol of $42^{\circ} \mathrm{C}$ incubation for $60 \mathrm{~min}$, followed by $10 \mathrm{~min}$ incubation at $70^{\circ} \mathrm{C}$. qPCR was performed using the BioEasy SYBR Green I Real Time PCR kit (BIOER) and a Line-Gene sequence detector (BIOER). The amplification reaction consisted of 45 cycles of 
$95^{\circ} \mathrm{C}$ for $20 \mathrm{sec}, 60^{\circ} \mathrm{C}$ for $25 \mathrm{sec}$ and $72^{\circ} \mathrm{C}$ for $30 \mathrm{sec}$. PCR products were detected by the incorporation of SYBR Green during the reaction and verified by generating an amplification curve and by gel electrophoresis. The primer sequences for RAGE, MCP-1 and glyceraldehyde-3-phosphate dehydrogenase (GAPDH) are provided in Table I. Amplification products were quantified relative to the level of GAPDH, using the $2^{-\Delta \Delta C q}$ method (18).

Western blot analysis. Frozen spinal cord tissue was homogenized in ice-cold isolation buffer containing $250 \mathrm{mmol} / \mathrm{l}$ sucrose, $10 \mathrm{mmol} / 1$ triethanolamine, $1 \mathrm{mg} / \mathrm{ml}$ leupeptin and $0.1 \mathrm{mg} / \mathrm{ml}$ phenylmethylsulfonyl fluoride. Homogenates were centrifuged at $15,000 \times \mathrm{g}$ for $10 \mathrm{~min}$ at $4^{\circ} \mathrm{C}$, and the protein concentration in the supernatant was measured using a bicinchoninic acid protein quantitation kit (Beijing Sunbio Biotech Co., Ltd., Beijing, China). Total protein $(50 \mu \mathrm{g})$ in each sample was resolved by $12 \%$ sodium dodecyl sulfate-polyacrylamide gel electrophoresis and transferred to polyvinylidene difluoride membranes. Membranes were blocked in 5\% skimmed milk powder for $2 \mathrm{~h}$ at room temperature, then incubated overnight at $4^{\circ} \mathrm{C}$ with primary antibodies against RAGE $(1: 1,000$; catalog no. sc-365154; Santa Cruz Biotechnology, Inc.), MCP-1 (1:2,000; catalog no. sc-28879; Santa Cruz Biotechnology, Inc.), or actin (1:2,000; catalog no. sc-1616R; Santa Cruz Biotechnology, Inc.) as indicated. Membranes were washed, then incubated with horseradish peroxidase-conjugated secondary antibodies (catalog nos. sc-2004 and sc-2005; Santa Cruz Biotechnology, Inc.) diluted to 1:10,000 for $2 \mathrm{~h}$ at $37^{\circ} \mathrm{C}$, and immunoreactive protein was visualized using an enhanced chemiluminescence western blotting detection system (BestBio Inc., Shanghai, China). The film was scanned (Konica Minolta Medical Imaging, Inc., Wayne, NJ, USA), and protein expression was quantified from 2 blots using Adobe Photoshop CS2 (Adobe Systems Inc., San Jose, CA, USA) and LabWorks (UVP, Inc., Upland, CA, USA).

Statistical analysis. Data are presented as the mean \pm standard deviation of 3 replicates. One-way analysis of variance was used to compare the mean responses between the treatments, followed by least significant difference or Student-Newman-Keuls post hoc tests. $\mathrm{P}<0.05$ was considered to indicate a statistically significant difference. Analyses were performed using SPSS (v15.0; SPSS Inc., Chicago, IL, USA).

\section{Results}

HBO promotes recovery of locomotor function following SCI. To evaluate the extent of locomotor function, BBB locomotor scores were calculated for control and experimental animals. As demonstrated in Fig. 1, the mean BBB scores of the SCI and $\mathrm{SCI}+\mathrm{HBO}$ groups were significantly lower than those of the $\mathrm{SH}$ group at every time point $(\mathrm{P}<0.01)$. BBB scores in rats in the SCI and SCI + HBO groups improved from day 3, though the rats in the SCI + HBO group improved more rapidly; statistical analysis indicated a significantly greater increase in the $\mathrm{BBB}$ score in the $\mathrm{SCI}+\mathrm{HBO}$ group compared with the SCI group on days 7 and $14(\mathrm{P}=0.006$ and $\mathrm{P}=0.001$, respectively; Fig. 1), indicating that $\mathrm{HBO}$ therapy promotes locomotor function in rats with SCI.
Table I. Sequences of primers for reverse transcription-quantitative polymerase chain reaction.

\begin{tabular}{ll} 
Target gene & \multicolumn{1}{c}{ Sequence (5'-3') } \\
\hline RAGE & F-AGAAACCGGTGATGAAGGACAA \\
& R-TCGTTTTCGCCACAGGATGG \\
MCP-1 & F-TCTGGGCCTGTTGTTCACAGT \\
& R-TGCTGCTGGTGATTCTCTTGTAGT \\
GAPDH & F-GCAAGTTCAACGGCACAG \\
& R-CGCCAGTAGACTCCACGAC
\end{tabular}

RAGE, receptor for advanced glycation end products; MCP-1, monocyte chemoattractant protein-1; GAPDH, glyceraldehyde 3-phosphate dehydrogenase.

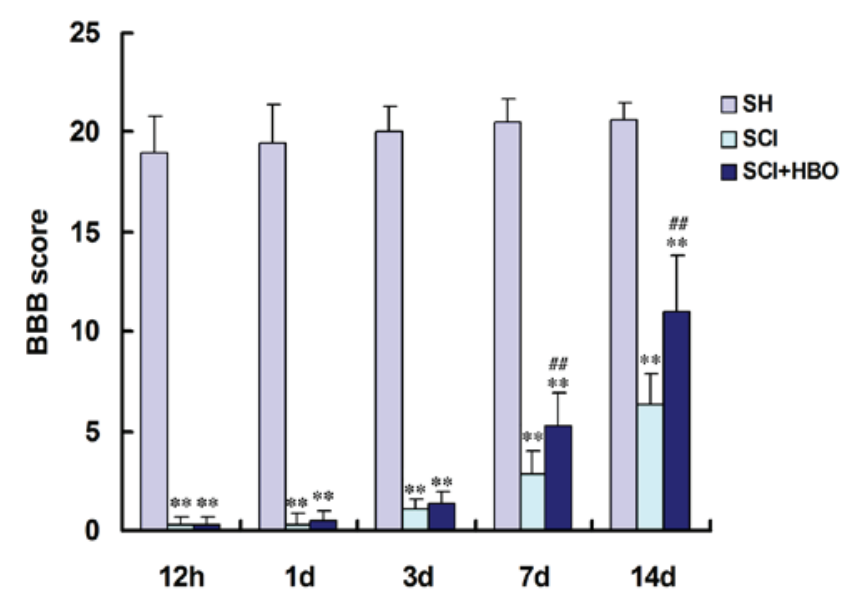

Figure 1. Locomotor function recovery assessment via BBB scores for hind limb motor function in the SH, SCI and SCI + HBO groups $(\mathrm{n}=6$ for each group) at $12 \mathrm{~h}$, and 1, 3, 7 and 14 days post-injury. Values are expressed as the mean \pm standard deviation. ${ }^{* *} \mathrm{P}<0.01$ vs. $\mathrm{SH}$ group. ${ }^{\# \#} \mathrm{P}<0.01$ vs. SCI group. BBB, Basso, Beattie and Bresnahan; SH, sham-operated; SCI, spinal cord injury; HBO, hyperbaric oxygen.

$H B O$ reduces neutrophil infiltration following SCI. The effect of HBO therapy on neutrophil infiltration was assessed via MPO activity assays at multiple time points following SCI. The MPO activity was significantly increased in the SCI and SCI + HBO groups compared with the SH group at each post-operative time point (Fig. 2). However, the MPO activity of the SCI + HBO group was significantly lower than the SCI group at all time points from day 1 (Fig. 2), suggesting that HBO therapy reduces neutrophil infiltration following SCI.

HBO suppresses the expression of RAGE and MCP-1 following SCI. Immunohistochemistry was then used to detect RAGE and MCP-1 expression and localization. As demonstrated in Fig. 3A, RAGE and MCP-1 were predominantly expressed in the grey matter. RAGE- and MCP-1-positive cells were detectable in the $\mathrm{SH}$ group at all time points, however, the proportion of RAGE- and MCP-1-positive cells was significantly higher following SCI, with or without HBO therapy, with the exception of MCP-1 on day 14 (Fig. 3B). However, the proportion of RAGE- and MCP-1-positive cells was 


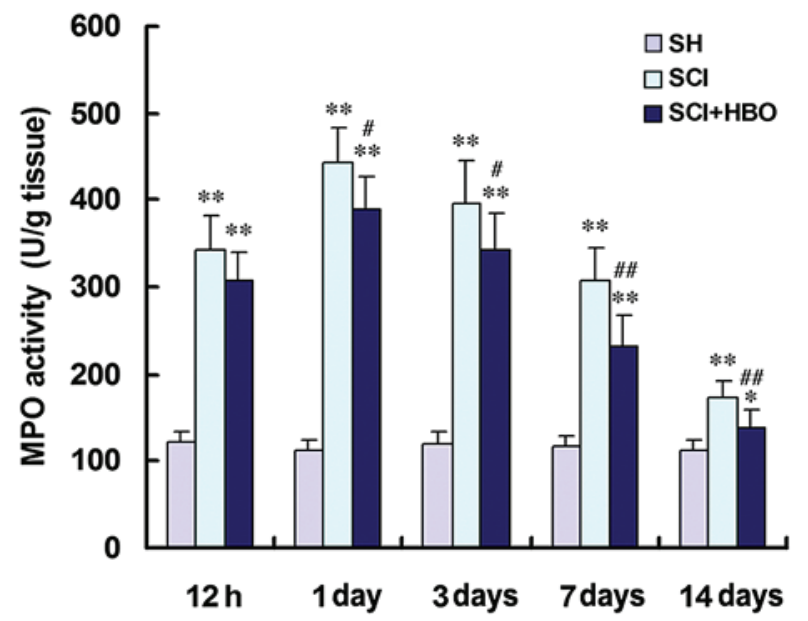

Figure 2. MPO activity in SCI and HBO-treated rats. Values are expressed as the mean \pm standard deviation. ${ }^{*} \mathrm{P}<0.05,{ }^{* *} \mathrm{P}<0.01$ vs. $\mathrm{SH}$ group. ${ }^{\#} \mathrm{P}<0.05$, ${ }^{\# \#} \mathrm{P}<0.01$ vs. SCI group. MPO, myeloperoxidase; $\mathrm{SH}$, sham-operated; SCI, spinal cord injury; HBO, hyperbaric oxygen.

significantly lower in the SCI + HBO group compared with the SCI group at all time points from day 1, with the exception of MCP-1 on day 14 (Fig. 3B).

RAGE and MCP-1 mRNA and protein expression levels were then assessed by RT-qPCR (Fig. 4) and western blot (Fig. 5), respectively. RAGE and MCP-1 mRNA and protein expression levels were consistently low in the SH group (Figs. 4 and 5, respectively). Following SCI, RAGE and MCP-1 mRNA and protein expression levels were significantly increased at $12 \mathrm{~h}$ compared with the $\mathrm{SH}$ group, reaching their maximum level at the 1 day time point (Figs. 4 and 5, respectively). RAGE and MCP-1 mRNA and protein levels were significantly higher in the SCI group compared with the SH group at $12 \mathrm{~h}$, and days 1,3 and 7 post-operatively (all $\mathrm{P}<0.01$; Figs. 4 and 5, respectively). On day 14, the expression of RAGE mRNA ( $\mathrm{P}<0.0001$; Fig. 4), RAGE protein ( $\mathrm{P}<0.0001$; Fig. 5) and MCP-1 protein $(\mathrm{P}=0.021$; Fig. 5) was increased in the SCI group compared with the SH group. However, the expression levels of RAGE and MCP-1 mRNA (Fig. 4) and protein (Fig. 5) were significantly lower in the SCI + HBO group on days 3 and 7 post-surgery compared with the SCI group. RAGE mRNA expression levels were significantly reduced in the SCI + HBO group compared with the SCI group from day 3 ( $\mathrm{P}<0.05$; Fig. 4$)$ as were protein expression levels from day 1 ( $\mathrm{P}<0.05$; Fig. $5 \mathrm{~B})$. MCP-1 mRNA expression levels were significantly reduced in the SCI + HBO group compared with the SCI group on days 1,3 and $7(\mathrm{P}<0.05$; Fig. 4) as were protein expression levels on days $1,3,7$ and $14(\mathrm{P}<0.05$; Fig. 5). These data suggest that HBO therapy suppresses the expression of RAGE and MCP-1 following SCI.

\section{Discussion}

Numerous studies have demonstrated that mechanical injury following SCI results in secondary injuries, including inflammatory responses, hemorrhage, ischemia, excessive free radical generation, vascular dysregulation, and immune cell infiltration $(19,20)$. Specifically, inflammation following SCI is important for the regulation of remyelination and in neuronal and glial cell death $(21,22)$. Therefore, the inhibition of the inflammatory response is an important factor in neuroprotection and for promoting the recovery of locomotor function.

HBO therapy is a clinical therapy that involves administering $100 \%$ oxygen at a pressure higher than atmospheric pressure at sea level for a prescribed amount of time (23). HBO therapy is a well established treatment for acute and chronic SCI (3,24-26). Exposure to HBO decreases the expression levels of superoxide dismutase, glutathione peroxidase and nitric oxide synthase, relieves secondary inflammatory responses, inhibits apoptosis following injury and promotes the regeneration of nerve tissue (3,24-26). Previous studies have demonstrated that $\mathrm{HBO}$ relieves secondary inflammatory responses by decreasing the expression of NF- $\mathrm{B}, \mathrm{HMGB} 1$, Toll-like receptor 2 , interleukin-1 $\beta$ (IL-1 $\beta$ ), and tumor necrosis factor- $\alpha$ (TNF- $\alpha$ ) following SCI $(27,28)$. In addition, Chen et al (29) reported that exposure to HBO attenuates inflammation, as indicated by reduced expression of MCP-1 and other inflammatory cytokines in a traumatic brain injury model. However, the effect of HBO therapy on the expression of RAGE and MCP-1 following SCI remains unclear. Following SCI, the inflammatory response becomes intense and is most destructive within the initial few days following injury (30). Thus, in the present study, the anti-inflammatory and neuroprotective effects of $\mathrm{HBO}$ were measured during the early phase of SCI (12 h-14 days). Application of HBO following SCI was revealed to inhibit the infiltration of neutrophils, suppress the expression of inflammatory cytokines (including RAGE and MCP-1), and promote the recovery of locomotor function. To the best of our knowledge, this is the first study to examine the effect of HBO therapy on RAGE and MCP-1 expression following SCI.

Neutrophils are critical cellular components of the inflammatory response and the first inflammatory cell type to reach damaged tissue (31). Activated neutrophils promote tissue repair by inducing the phagocytosis of necrotic tissue in the wound area, while simultaneously promoting the release of elastase via a respiratory burst and producing large amounts of reactive oxygen species (ROS) (32). These ROS induce two effects: i) They attack the polyunsaturated fatty acids on the cell membrane, causing lipid peroxidation and disrupting the cell osmotic balance; and ii) they activate complement systems, resulting in a positive feedback loop in which neutrophils are further activated to produce more $\operatorname{ROS}(22,32)$. These downstream effects expand the inflammatory response and exacerbate secondary injury $(31,32)$. The results of the present study reveal that HBO therapy significantly inhibits the activity of neutrophils following SCI, which reduces secondary injury and provides a neuroprotective effect.

RAGE, a transmembrane protein and member of the immunoglobulin superfamily, is expressed in endothelial cells, neurons, macrophages and monocytes (33). RAGE is involved in various inflammatory mechanisms and participates in numerous diseases, including CNS disorders, by binding to diverse ligands. In particular, several studies have reported that RAGE was upregulated following SCI in rats and mice $(10,34)$. In confirmatory studies using RAGE-deficient animals, RAGE was demonstrated to be involved in various pathophysiological processes of SCI (35). In the present study, RAGE expression was demonstrated to be significantly increased from $12 \mathrm{~h}$ 
A
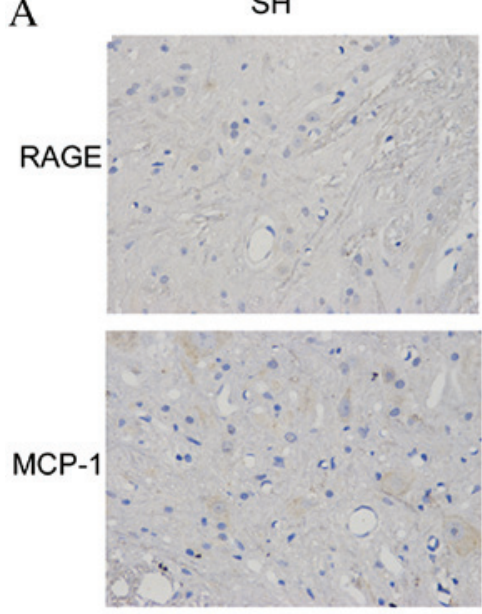

B

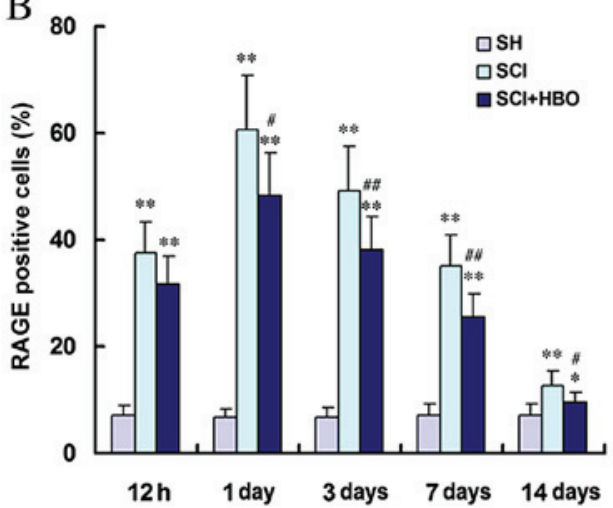

$\mathrm{SCl}$
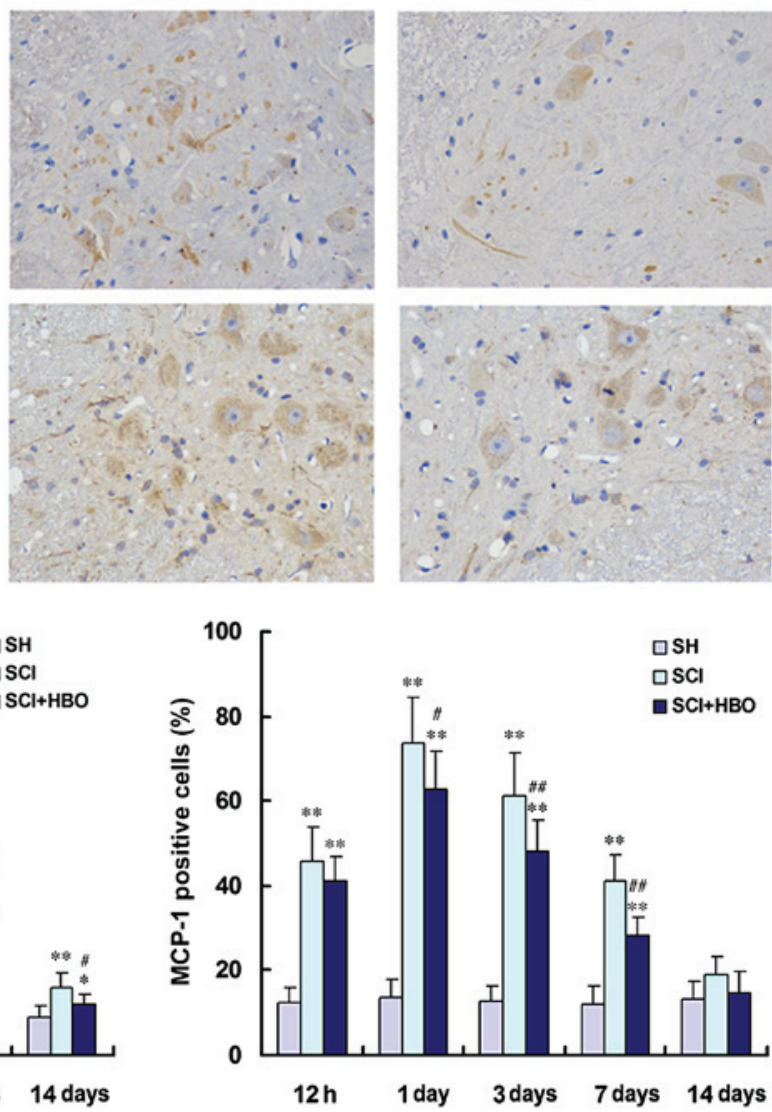

Figure 3. Expression of RAGE and MCP-1 in the control and experimental groups. (A) Representative photomicrographs of RAGE and MCP-1 immunohistochemistry in the spinal cord at 1 day post-surgery (original magnification, $\mathrm{x} 400$ ). (B) RAGE- and MCP-1-positive cells were quantified at $\mathrm{x} 400 \mathrm{magnification}$. Values are expressed as the mean \pm standard deviation. ${ }^{*} \mathrm{P}<0.05,{ }^{* *} \mathrm{P}<0.01$ vs. SH group. ${ }^{*} \mathrm{P}<0.05,{ }^{\# \#} \mathrm{P}<0.01$ vs. SCI group. SH, sham-operated; SCI, spinal cord injury; HBO, hyperbaric oxygen; RAGE, receptor for advanced glycation end products; MCP-1, monocyte chemoattractant protein-1.
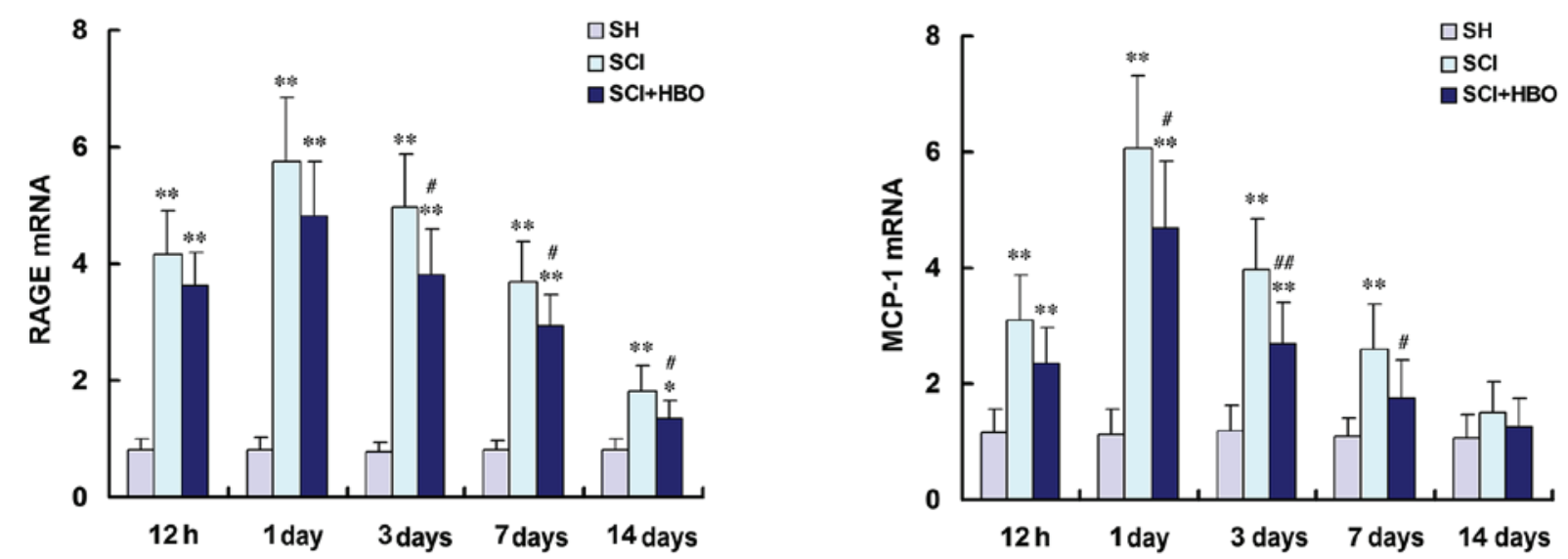

Figure 4. Expression levels of RAGE and MCP-1 mRNA in the spinal cord were determined by reverse transcription-quantitative polymerase chain reaction at the indicated time points. Values are expressed as the mean \pm standard deviation. ${ }^{~} \mathrm{P}<0.05,{ }^{* *} \mathrm{P}<0.01$ vs. SH group. ${ }^{\#} \mathrm{P}<0.05$, ${ }^{\# \#} \mathrm{P}<0.01$ vs. SCI group. RAGE, receptor for advanced glycation end products; SH, sham-operated; SCI, spinal cord injury; HBO, hyperbaric oxygen; MCP-1, monocyte chemoattractant protein-1.

following SCI and persisted for 14 days. RAGE expression was further observed to be significantly decreased in animals with SCI that were treated with HBO therapy compared with untreated animals with SCI. HBO administration following SCI was also demonstrated to reduce neutrophil infiltration and increase the BBB scores of injured rats. Therefore, it is surmised that decreased expression of RAGE as a result of HBO therapy may contribute to a reduced inflammatory response and an improvement in the restoration of locomotor function. Following binding to ligands including HMGB1 and S100 $\beta$, RAGE triggers the activation of NF- $\kappa \mathrm{B}$, induces the production of pro-inflammatory cytokines, including IL-1 $\beta$, 

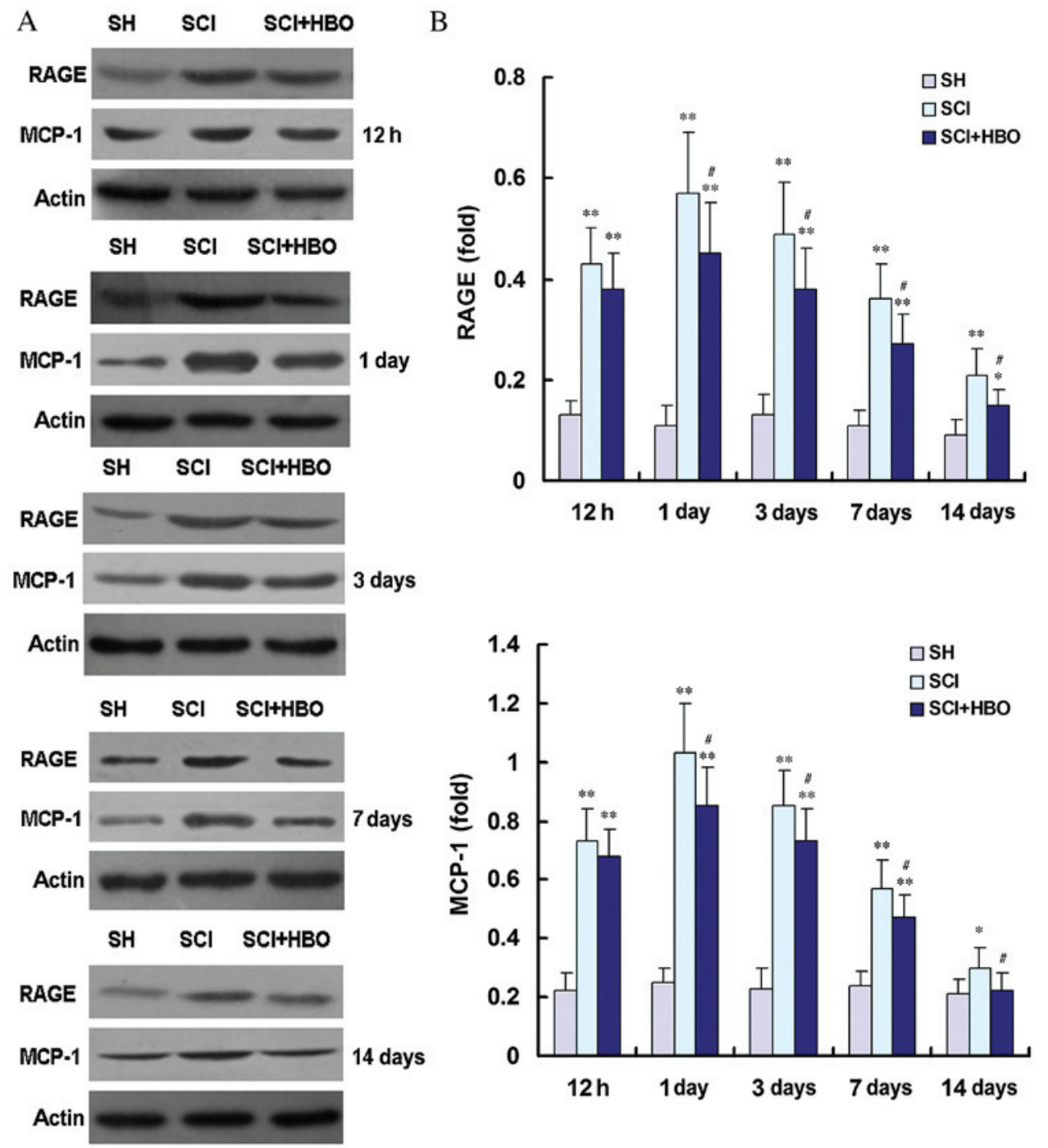

Figure 5. RAGE and MCP-1 protein expression levels in the spinal cord. (A) Representative immunoblots of RAGE and MCP-1 protein expression. (B) Quantitative analysis of RAGE and MCP-1 protein expression levels, relative to actin. Values are expressed as the mean \pm standard deviation. "P<0.05, ${ }^{* *} \mathrm{P}<0.01$ vs. SH group. ${ }^{*} \mathrm{P}<0.05$ vs. SCI group. RAGE, receptor for advanced glycation end products; MCP-1, monocyte chemoattractant protein-1; SH, sham-operated; SCI, spinal cord injury; HBO, hyperbaric oxygen.

IL-6 and TNF- $\alpha$, and causes inflammation (36). The expression of RAGE is also controlled by NF- $\mathrm{KB}$ transcription factor (7). Therefore, RAGE is upregulated in environments that are rich in RAGE ligands (37). Previous studies by this group have demonstrated that HBO therapy decreases the expression of NF- $\kappa B$ and HMGB1 following SCI $(27,28)$. These results may, therefore, partially explain why HBO therapy dramatically relieves RAGE expression following SCI.

MCP-1 is a potent chemoattractant with a significant role in recruiting lymphocytes and monocytes into inflammatory sites. In the CNS, MCP-1 is produced by a variety of cells, including reactive astrocytes, neurons, activated microglia and endothelial cells (38). Several recent studies have reported upregulation of MCP-1 expression following SCI in rats $(39,40)$. Inhibition of MCP-1 also attenuates leukocyte infiltration and tissue destruction in SCI (41). In the present study, the expression of MCP-1 was significantly increased following SCI, beginning at $12 \mathrm{~h}$, peaking at day 1 , and gradually declining to control levels by day 14; these findings are consistent with those of previous studies (42). Furthermore, HBO therapy significantly decreased the expression of MCP-1 in animals with $\mathrm{SCI}$ that were treated with $\mathrm{HBO}$ therapy compared with untreated animals in the SCI group. HBO therapy-mediated attenuation of neutrophil infiltration was also observed. Therefore, is it proposed that HBO therapy inhibits the expression of MCP-1 and that this change in MCP-1 is important in reducing the inflammatory response following SCI. This method may, therefore, be beneficial in promoting the recovery of locomotor function in rats with SCI. The question of how HBO therapy influences MCP-1 expression following SCI requires further investigation.

In conclusion, exposure to $\mathrm{HBO}$ following $\mathrm{SCI}$ has been demonstrated to reduce secondary inflammatory responses by decreasing the expression of RAGE and MCP-1, resulting in a significant restoration of locomotor function. These results are preliminary, however, they provide an important insight into the molecular mechanism by which HBO therapy promotes locomotor recovery in SCI rats, and may be useful for improving the clinical application of HBO in human patients with SCI. Further study will be required to elucidate the 
mechanism by which HBO therapy influences the expression of RAGE and MCP-1 following SCI.

\section{References}

1. Beattie MS, Hermann GE, Rogers RC and Bresnahan JC: Cell death in models of spinal cord injury. Prog Brain Res 137: 37-47, 2002.

2. Nie H, Xiong L, Lao N, Chen S, Xu N and Zhu Z: Hyperbaric oxygen preconditioning induces tolerance against spinal cord ischemia by upregulation of antioxidant enzymes in rabbits. J Cereb Blood Flow Metab 26: 666-674, 2006.

3. Dayan K, Keser A, Konyalioglu S, Erturk M, Aydin F, Sengul G and Dagci T: The effect of hyperbaric oxygen on neuroregeneration following acute thoracic spinal cord injury. Life Sci 90: 360-364, 2012.

4. Nakamura M, Houghtling RA, MacArthur L, Bayer BM and Bregman BS: Differences in cytokine gene expression profile between acute and secondary injury in adult rat spinal cord. Exp Neurol 184: 313-325, 2003.

5. Fritz G: RAGE: A single receptor fits multiple ligands. Trends Biochem Sci 36: 625-632, 2011.

6. Xie J, Mendez JD, Méndez-Valenzuela V and Aguilar-Hernández MM: Cellular signalling of the receptor for advanced glycation end products (RAGE). Cell Signal 25: 2185-2197, 2013.

7. Lin L, Park S and Lakatta EG: RAGE signaling in inflammation and arterial aging. Front Biosci (Landmark Ed) 14: 1403-1413, 2009.

8. Gao TL, Yuan XT, Yang D, Dai HL, Wang WJ, Peng X, Shao HJ, Jin ZF and Fu ZJ: Expression of HMGB1 and RAGE in rat and human brains after traumatic brain injury. J Trauma Acute Care Surg 72: 643-649, 2012

9. Muhammad S, Barakat W, Stoyanov S, Murikinati S, Yang H, Tracey KJ, Bendszus M, Rossetti G, Nawroth PP, Bierhaus A and Schwaninger M: The HMGB1 receptor RAGE mediates ischemic brain damage. J Neurosci 28: 12023-12031, 2008.

10. Chen KB, Uchida K, Nakajima H, Yayama T, Hirai T, Rodriguez Guerrero A, Kobayashi S, Ma WY, Liu SY, Zhu P and Baba H: High-mobility group box-1 and its receptors contribute to proinflammatory response in the acute phase of spinal cord injury in rats. Spine (Phila Pa 1976) 36: 2122-2129, 2011.

11. Kwon BK, Stammers AM, Belanger LM, Bernardo A, Chan D, Bishop CM, Slobogean GP, Zhang H, Umedaly H, Giffin M, et al: Cerebrospinal fluid inflammatory cytokines and biomarkers of injury severity in acute human spinal cord injury. J Neurotrauma 27: 669-682, 2010.

12. Liu SQ, Ma YG, Peng H and Fan L: Monocyte chemoattractant protein-1 level in serum of patients with acute spinal cord injury. Chin J Traumatol 8: 216-219, 2005.

13. Galasso JM, Liu Y, Szaflarski J, Warren JS and Silverstein FS Monocyte chemoattractant protein-1 is a mediator of acute excitotoxic injury in neonatal rat brain. Neuroscience 101: 737-744, 2000.

14. Allen EA, Erhardt EB and Calhoun VD: Data visualization in the neurosciences: Overcoming the curse of dimensionality. Neuron 74: 603-608, 2012.

15. Basso DM, Beattie MS and Bresnahan JC: A sensitive and reliable locomotor rating scale for open field testing in rats. J Neurotrauma 12: 1-21, 1995.

16. Yang L, Jones NR, Blumbergs PC, Van Den Heuvel C, Moore EJ, Manavis J, Sarvestani GT and Ghabriel MN: Severity-dependent expression of pro-inflammatory cytokines in traumatic spinal cord injury in the rat. J Clin Neurosci 12: 276-284, 2005.

17. Anik I, Kokturk S, Genc H, Cabuk B, Koc K, Yavuz S, Ceylan S, Ceylan S, Kamaci L and Anik Y: Immunohistochemical analysis of TIMP-2 and collagen types I and IV in experimental spinal cord ischemia-reperfusion injury in rats. J Spinal Cord Med 34: 257-264, 2011

18. Livak KJ and Schmittgen TD: Analysis of relative gene expression data using real-time quantitative PCR and the 2(-Delta Delta C(T)) Method. Methods 25: 402-408, 2001.

19. Kwon BK, Tetzlaff W, Grauer JN, Beiner J and Vaccaro AR: Pathophysiology and pharmacologic treatment of acute spinal cord injury. Spine J 4: 451-464, 2004.

20. Sinescu C, Popa F, Grigorean VT, Onose G, Sandu AM, Popescu M, Burnei G, Strambu V and Popa C: Molecular basis of vascular events following spinal cord injury. J Med Life 3: 254-261, 2010
21. Miron VE, Boyd A, Zhao JW, Yuen TJ, Ruckh JM, Shadrach JL, van Wijngaarden P, Wagers AJ, Williams A, Franklin RJ and ffrench-Constant C: M2 microglia and macrophages drive oligodendrocyte differentiation during CNS remyelination. Nat Neurosci 16: 1211-1218, 2013.

22. Xue H, Zhang XY, Liu JM, Song Y, Liu TT and Chen D: NDGA reduces secondary damage after spinal cord injury in rats via anti-inflammatory effects. Brain Res 1516: 83-92, 2013.

23. Tibbles PM and Edelsberg JS: Hyperbaric-oxygen therapy. N Engl J Med 334: 1642-1648, 1996.

24. Topuz K, Colak A, Cemil B, Kutlay M, Demircan MN, Simsek H, Ipcioglu O, Kucukodaci Z and Uzun G: Combined hyperbaric oxygen and hypothermia treatment on oxidative stress parameters after spinal cord injury: An experimental study. Arch Med Res 41: 506-512, 2010.

25. Liu X, Zhou Y, Wang Z, Yang J, Gao C and Su Q: Effect of VEGF and CX43 on the promotion of neurological recovery by hyperbaric oxygen treatment in spinal cord-injured rats. Spine J 14: 119-127, 2014.

26. Lu PG, Feng H, Yuan SJ, Zhang RW, Li M, Hu R, Liu ZS and Yin J: Effect of preconditioning with hyperbaric oxygen on neural cell apoptosis after spinal cord injury in rats. J Neurosurg Sci 57: 253-258, 2013.

27. Yang J, Liu X, Zhou Y, Wang G, Gao C and Su Q: Hyperbaric oxygen alleviates experimental (spinal cord) injury by downregulating HMGB1/NF-кB expression. Spine (Phila Pa 1976) 38: E1641-E1648, 2013.

28. Tan J, Zhang F, Liang F, Wang Y, Li Z, Yang J and Liu X: Protective effects of hyperbaric oxygen treatment against spinal cord injury in rats via toll-like receptor $2 /$ nuclear factor- $\mathrm{\kappa B}$ signaling. Int J Clin Exp Pathol 7: 1911-1919, 2014

29. Chen X, Duan XS, Xu LJ, Zhao JJ, She ZF, Chen WW, Zheng ZJ and Jiang GD: Interleukin-10 mediates the neuroprotection of hyperbaric oxygen therapy against traumatic brain injury in mice. Neuroscience 266: 235-243, 2014.

30. Leskovar A, Moriarty LJ, Turek JJ, Schoenlein IA and Borgens RB: The macrophage in acute neural injury: Changes in cell numbers over time and levels of cytokine production in mammalian central and peripheral nervous systems. J Exp Biol 203: 1783-1795, 2000.

31. Tjoa T, Strausbaugh HJ, Maida N, Dazin PF, Rosen SD and Noble-Haeusslein LJ: The use of flow cytometry to assess neutrophil infiltration in the injured murine spinal cord. J Neurosci Methods 129: 49-59, 2003

32. Carlson SL, Parrish ME, Springer JE, Doty K and Dossett L: Acute inflammatory response in spinal cord following impact injury. Exp Neurol 151: 77-88, 1998.

33. Stern D, Yan SD, Yan SF and Schmidt AM: Receptor for advanced glycation endproducts: A multiligand receptor magnifying cell stress in diverse pathologic settings. Adv Drug Deliv Rev 54: 1615-1625, 2002.

34. Kawabata H, Setoguchi T, Yone K, Souda M, Yoshida H, Kawahara K, Maruyama I and Komiya S: High mobility group box 1 is upregulated after spinal cord injury and is associated with neuronal cell apoptosis. Spine (Phila Pa 1976) 35: 1109-1115, 2010.

35. Guo JD, Li L, Shi YM, Wang HD, Yuan YL, Shi XX and Hou SX: Genetic ablation of receptor for advanced glycation end products promotes functional recovery in mouse model of spinal cord injury. Mol Cell Biochem 390: 215-223, 2014.

36. Li H, Wu W, Sun Q, Liu M, Li W, Zhang XS, Zhou ML and Hang CH: Expression and cell distribution of receptor for advanced glycation end-products in the rat cortex following experimental subarachnoid hemorrhage. Brain Res 1543: 315-323, 2014.

37. Schmidt AM, Yan SD, Yan SF and Stern DM: The multiligand receptor RAGE as a progression factor amplifying immune and inflammatory responses. J Clin Invest 108: 949-955, 2001.

38. Che X, Ye W, Panga L, Wu DC and Yang GY: Monocyte chemoattractant protein-1 expressed in neurons and astrocytes during focal ischemia in mice. Brain Res 902: 171-177, 2001.

39. Stammers AT, Liu J and Kwon BK: Expression of inflammatory cytokines following acute spinal cord injury in a rodent model. J Neurosci Res 90: 782-790, 2012.

40. Sandhir R, Gregory E, He YY and Berman NE: Upregulation of inflammatory mediators in a model of chronic pain after spinal cord injury. Neurochem Res 36: 856-862, 2011

41. Zhang X, Chen C, Ma S, Wang Y and Su X: Inhibition of monocyte chemoattractant peptide-1 decreases secondary spinal cord injury. Mol Med Rep 11: 4262-4266, 2015.

42. McTigue DM, Tani M, Krivacic K, Chernosky A, Kelner GS, Maciejewski D, Maki R, Ransohoff RM and Stokes BT: Selective chemokine mRNA accumulation in the rat spinal cord after contusion injury. J Neurosci Res 53: 368-376, 1998. 